\title{
Technologies for reducing emissions and costs in combined heat and power production
}

\author{
Harri Auvinen ${ }^{1, *}$, Ulla Santti ${ }^{1, *}$, and Ari Happonen ${ }^{2, *}$ \\ ${ }^{1}$ Savonia, PL 6 (Microkatu 1), 70201 Kuopio, Finland \\ ${ }^{2}$ LUT University, School of Engineering Science, 53850 Lappeenranta, Finland
}

\begin{abstract}
According Finnish Energy association, in Finland roughly three-quarters of district heat production is based on combined heat and power (CHP) generation. Correspondingly, one-third of electricity is generated using CHP. In Finland, the market share of CHP derived electricity is significant, and therefore used technologies and fuels should be carefully chosen in terms of costs and emissions. In this paper we consider a case of Kuopio, which is the $9^{\text {th }}$ biggest city in Finland. In the past few years, the total usage of fossil fuels has been decreasing and the use of renewable fuels has correspondingly been increasing. The amount of electricity produced with peat has gradually decreased during the last 15 years. The common explaining factor for these trends is the political will and national and municipal level shared common aim to reduce greenhouse gases and emissions. Furthermore, there are new technical innovations available, such as flue gas scrubber and district cooling system, which has been proven to be significant tools to reduce emission and at the same time investments into these innovations have been shown to save energy and money, meaning being greener has been also financially lucrative decision for these sustainability enhancing technology investors.
\end{abstract}

\section{Introduction}

There are multiple inevitable proofs for the climate change, global warming and ecological responses for those are visible too, thus humankind should take an effective implementation of practical actions for many species survival [1-5]. Positively thinking, the fight against the climate change is not yet over or lost and e.g. through technological development and adopting of these new technologies by public and private companies, true positive results can be gained. $12^{\text {th }}$ Dec 2015 concluded Paris Agreement and signed over 190 countries [6] aiming to pursue efforts to mitigate global warming by 1,5 degrees [7] and we also should not forget sustainable food production and economic development in reduction of GHG emissions [8]. United Nations Sustainable Development Goals (SDGs) are 17 globally set goals by 2030 answering challenges of poverty, inequality, climate, environmental degradation, prosperity, peace and justice [9]. Aim of SDGs is to create welfare and sustainable future for all on earth. In energy sector SGDs means access to basic energy, energy for economic development, sufficiency, renewable energy, infrastructure, greenhouse gas emissions, efficiency and security, which can be reached through enabling goals: investment \& finance, public policy, institutions \& governance, capacity \& knowledge [10].

Many times, the climate change related matters are discussed in private persons point of view, how we as consumers could use less resources, do source waste separation to help municipalities to run more efficient recycling processes and so on, but this is not all. The Climate change is not only private persons concern and according to scientists, companies have been slow to give effective answers for it and policy makers should require decent impact measurement system [11]. We cannot go back to stone age and stop the economic growth, which brings more pollution and therefore we have two sort of short term viable options: 1) reduce the carbon intensity of energy use or 2) reduce energy intensity [12]. Many scientists and populist do talk about few other options too, like reducing the number of people in earth, (energy consuming) services people need, energy used by these services and finally $\mathrm{CO}_{2}$ produced per unit of energy. In a long run, "everything" could be solved if we could drive down the $\mathrm{CO}_{2}$ emissions produced by energy per unit to almost to zero at the same time when we drive down the cost of energy to near zero levels. For example, Bill Gates did put it like this "technical feasibility of deep decarbonization rests on the large-scale deployment of several low-carbon technologies, some of which are not yet fully commercialized or affordable" [13]. In this article, authors focus on tools and innovations which have been tested in first practical contexts and have now real number based researched facts to be discussed in academic manner. Purpose of this publication is to demonstrate how energy companies can increase energy efficiency and profit and at the same time decrease emissions by making sustainable technology investments. We have selected Kuopio

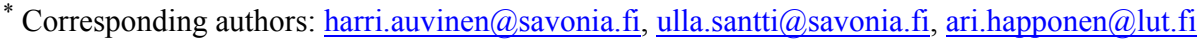


Energy's investments as a reference case with a verified data and actual costs.

\subsection{Bioenergy usage for renewable energy production in Finland}

In Finland bioenergy plays a big role in the renewable energy production. Bioenergy production is closely connected to a forestry and forest industry. Major share of wood-based fuels is derived from the side streams of the forest industry. When wood processing mills and factories converse raw food to value added products, they produce side streams like sawdust, bark and black liquor acquired from the pulp-making process. There are also several other biomass sources such as collected urban biowaste and wood harvesting and logging residues. According to data of Statistics Finland the total consumption of wood fuels was $105 \mathrm{TWh}$ in 2018, which was more than $1 / 4$ from the total. In fact, wood-based fuels represented the most important energy source in Finland, covering 27 per cent of the total energy consumption.

Finland aims is to increase the share of renewable energy. Related to this goal, the latest national Energy and Climate Strategy was adopted in November 2016. In this strategy, the target is to increase the use of renewable energy share so that it would reach 50 per cent during the next decade 2020. Following the set targets, nation took actions and in 2018 renewable energy share was already 37 per cent of gross energy consumption in Finland. In the $\mathrm{EU}$, the targets for renewable energy are established in relation to energy end-consumption, and in 2017 share of renewables was already as high as 40 per cent of endenergy consumption.

\subsection{Municipal level decision making, public sector investments and ecological effects}

Municipal infrastructure decision making includes processing and interpreting a large amount of fragmented data, which causes inefficiency in management strategies [14]. Considering the municipalities data and facts based decision challenges, it does not help at all that the trend in data amounts does not seem to decrease in the future either, so only option for the municipalities is to get more efficient and wiser on data analysis and more pedant on data source considerations. For example, according to City on Kuopio pro-active approach in evaluation of public decisionmaking effects has to be part of the process. Their point of view comes from fact, that the decisions effect in peoples' lives, environment, economy and companies and the City of Kuopio has included environmental aspect under heading 'resource wise' in the strategy with wise mobility, energy efficiency \& renewable energy and circular economy and resource wise use. There is also other good example about sustainable development activity in Finland in the City of Tampere, which has made Sustainable Development Commitment by 2050 in promoting sustainable business policy, resource-efficient economy and sustainable procurement in its operations and also challenging city's industries to make their own commitment [15]. These examples of sustainable progress can be led from Finnish Government, which has strengthen pro-active decision making role in strategy work to secure welfare society also in the future with government's foresight reporting, joint forecasting between ministries and also municipal strategic and foresight work [16].

On other hand, public funding alone will not be enough for the Finnish nation to be able to reach the United Nations Sustainable Development Goals (SDGs) by 2030. To solve the monetary limitations-based challenge, Finland has published a roadmap in line with SDGs in cooperation with public, private and third sector to take step towards globally influencing sustainable financing ecosystem [17]. These steps are: 1) a sufficient number and quality of investments, 2) instrument identification and customization, 3) convincing management, 4) influence reflected on SGDs 5) skills and knowledge [18].

\section{Decisions and investment actions to reduce emissions}

The climate political program of the city of Kuopio was updated in 2009. The city council did update their climate pollution prevention goals to reduce at least $40 \%$ of the greenhouse gases before 2020 from the level of the reference year 1990. In this geological region, energy production, housing and transportation are the major causes for the greenhouse gas emissions. Therefore, the actions of the local power plant (Kuopio energy) have the key roles in reducing the total amount of emissions produced in the region.

\subsection{General view into the municipal energy companies and sustainability related decisions}

Roelich \& Bale studied municipal energy companies in UK, including e.g. these companies' motivations and barriers, although they found a variety of benefits in lowcarbon transition, local authorities face challenges in matching their motivations to business models and more effective decision support tools would be needed [19]. Earlier research about corporate environmental management motivations and barriers indicated also cost barriers, external forces like competition, investor regulatory pressures, but also in addition, management attitudes affect company's environmental practices [20]. Also, East-English SME research found that the most motivating factor for managers to engage proenvironmental implementations is their own personal values and beliefs about the climate change [21].

In Kuopio (Eastern Finland) at the central parts of the city's urban areas, nine out of ten households are using district heating as house heating energy source. The district heating network has been built, renovated and extended in reach during a several decades and it is still constantly growing. For energy companies, being part of district heating system is a key ingredient for high energy efficiency rating. Combined heat and power production from energy plant can allow it to reach $90 \%$ energy efficiency. This efficiency is reached because otherwise wasted heat energy in electricity generation process can be now utilised as heating energy as part of the district heating 
system operations. In Finland there is a large amount of domestic bio-based fuels available.

Kuopio Energy ltd, owned by the City of Kuopio, produces electricity and district heat using combined heat and power production (CHP) process. Company uses mainly bio-based fuels for its CHP production units and these bio-based fuels are delivered from mainly nearby sources from the North Savo area. Kuopio Energy's subsidiary, Kuopion Sähköverkko ltd is responsible company for the electricity transmission from the plant to Finnish energy grid. Kuopio Energy ltd yearly electricity production is around $700 \mathrm{GWh}$ and it also produces around $900 \mathrm{GWh}$ of district heat in a year. Kuopio Energy serves roughly 50000 electricity and 6000 district heating customers, and the consortium employs approximately 160 people. CHP power plants are in an urban city area Haapaniemi (Figure 1.). Biogas power plant locates in Pitkälahti close to a sorting and environmental station of norther Savo region.

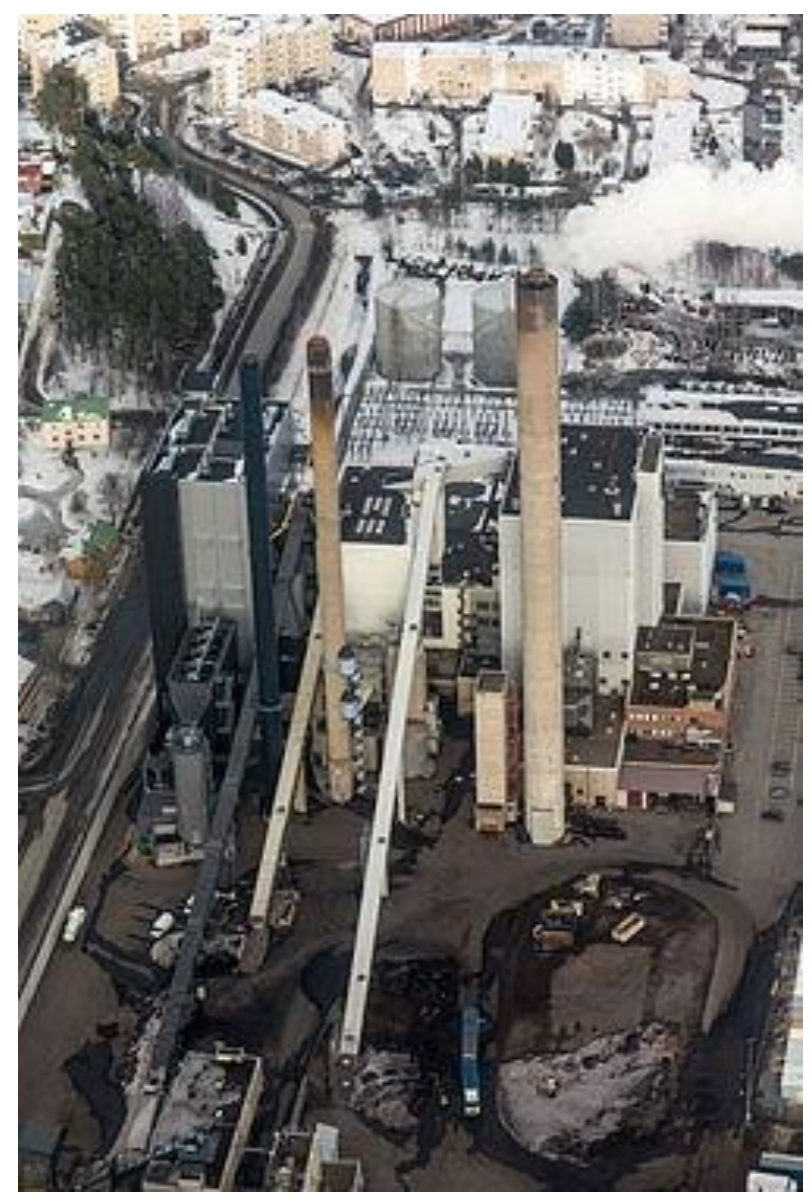

Fig. 1. CHP power plants in urban city area, Haapaniemi.

\subsection{Investments to enhance current energy production unit's efficiency and building of new}

During the resent years, Kuopio Energy Ltd has invested several millions for new energy production technologies. As part of this investment and energy efficiency efforts, the new Haapaniemi-3 CHP power plant was commissioned in 2011 (Figure 2). Haapaniemi-3 can utilize up to $75 \%$ renewable biofuels. Remain $25 \%$ is typically domestic peat. After the initial commission and first years of operations and process' fine tune actions in Haapaniemi-3, the burning technology used in powerplant nearby (Haapaniemi-2) was put under update process in year 2013. The update allows the Haapaniemi-2 unit to use up to $100 \%$ local renewable bio-based fuels. After starting to utilize these new units with their updates, the total share of renewables has increased above $50 \%$ and the company does not use hard coal anymore.

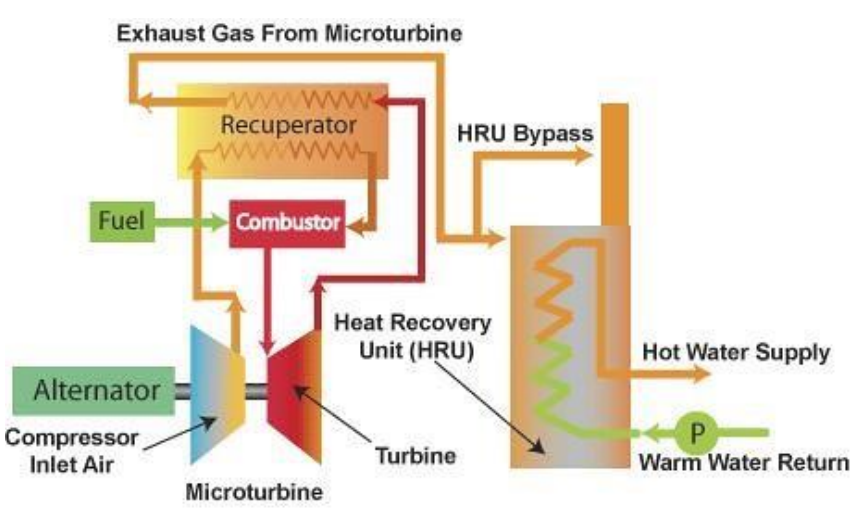

Fig. 2. Simplified CHP power systems.

\subsection{Investment on sustainability can be both ecologically beneficial and financially intriguing investment}

The previously mentioned improvements in burning units were not the only investments and actions city and the energy companies have been taking to be more efficient and sustainable in near future electricity and heating energy production actions. The flue gas scrubber investment (Figure 3.) was made roughly in the times when the Haapaniemi-2 update was processed and after finishing the scrubber unit it was finally connected to Haapaniemi-2 power plant in year 2015. This flue gas scupper unit uses special technology, which treatments and removes sulphur and particles from the flue gasses and by so doing reduces emissions significantly.

In addition to be environmentally friendly and sustainability supporting technology investment, the scrubber also enables additional capture capabilities for otherwise wasted heat, from the flue gasses. Heat capture from the flue gas increases the district heating power output for additional $50 \mathrm{MW}$ and it helps the company to save propellant roughly for $200000 \mathrm{MWh}$ in each year. This saving is equivalent with 1800 full truckloads of propellent, or other words it would provide enough heat for 9000 households for one full year, which alone is highly substantial gain in environmentally positive investment like this one. But that's not all, the reality is this investment cost will have impact to electricity and heat energy costs as it is directly connected to the energy plants.

The flue gas scrubber unit itself needed total investment of 11 million euros, to be implemented into the given plant process. From investment point of view, considering about the ROI (return of investment) value, due to heat the capturing, the scrubber will generate 
roughly 3 million euros revenue per each year. Given the revenues, the unit payed itself back roughly in 4 years, making it one of the most profitable investments municipalities typically could do in this price range. Currently, biggest challenge for why these investments are not happening "everywhere", seem to be the lack of knowledge. Also in Kuopio, there where decision makers who initially consider the flue gas scrubber as an additional cost and not as an investment which would decrease emissions and increase the profit of the company.

On other hand, the municipalities would need more data and knowledge about investments like these to make good and sustainable decisions [22]. On the other hand, the flue gas scrubber unit manufacturing companies should consider a move towards more digitalized units, units which would move their business model a step closer to knowledge companies [23] as the knowledge is something municipalities need now.

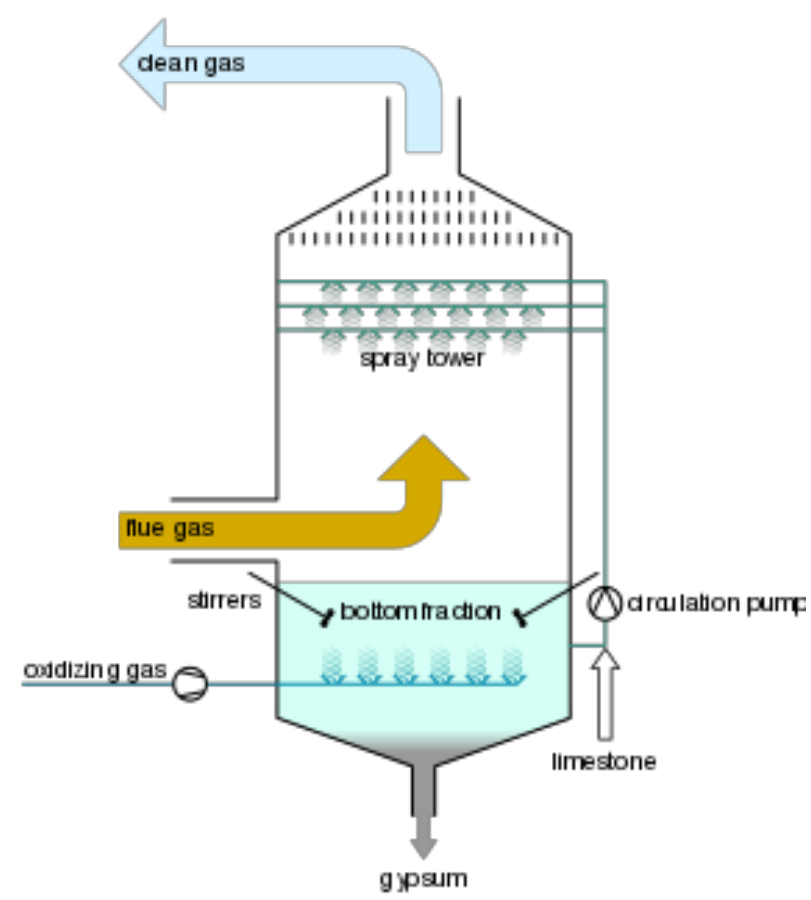

Fig. 3. Flue gas scrubber system removes sulphur and particles from the flue gasses.

\section{Discussion, future research possibilities considerations and holistic impact analysis ideas for municipalities}

Considering this sort of flue gas scrubber unit as environmentally friendly investment, which also makes clear ROI sense too, many people tend to forget what sort of other ramifications it might have. For example, one thing people usually do not even thing, when we point out saving like this, is the fact, that if sustainability supporting investment also generates more energy output, which contributes for 1800 truckload reduction, the investment has just generated additional reduction of $\mathrm{CO}_{2}$ emissions. Thinking in broader perspective, this same saving means less need for wood chopping in forest, less wasted fuel in harvesters and so on. Similar energy efficiency enhancing sustainability investments have long tail on $\mathrm{CO}_{2}$ emission reduction ramification effects. Because of this, in the future, it would be essential to try to model the whole chain from the forest, up until to the gas pipe of these energy generation units. Full chain modelling would help us to truly understand the total environmental potential these investments bring into municipalities decision tables.

From a technical point of view, the society we live into is constantly digitalizating in faster and faster speeds. It was mentioned previously that the challenge for municipalities, in decision making, is the huge amounts of data, and less and less simple readily condensed knowledge for different investment options. For this we would highly success e.g. Kuopio Energy ltd and as such the City of Kuopio add layers of data collection and then KPI (Key Performance Indicators) measurements into investments like these. Build them to be automatic and openly shared for general public to speed up knowledge sharing and open discussions on sustainable investments on energy production. As it is in this case, when city invests to units like these, they do it with tax payer's money. This money is paid back roughly already in 4 years, following multiple years of millions of euros investment payback per year, it would be highly important to share the knowledge and boost the dissemination of usability of this investment to large audience in global level.

Related to the environmental discussion, it is easy to get focused only into the environmental side, which is not the way to make responsible investments, especially when these investments are made from shared money, coming from taxpayers' "pockets". Responsible environmental investments should consider also the social, monetary and managerial aspects too, like currently in EU, Union is examining how to integrate sustainability considerations into its financial policy framework in order to mobilise finance for sustainable growth. Then coming back to municipalities level, the challenge on having "not enough" clear and well-studied information about sustainable investments, it is clear there is need and demand for accepted and scientifically tested methods to analysed these investments to produce clear aggregated knowledge on what sort of investment we area actually talking about, in big picture. Multi-criteria tool is commonly used to build different scenarios for decision making to increase effectiveness to save time and transparency to decision making process $[24,25]$. Interestingly enough, in citizen side, municipalities have been networking with Higher educational units to use hackathons $[26,27]$ as a tool to build educational and gamified solutions to boost up citizen waste recycling activities [28]. Seems like there is a need for municipalities to do similar thing in decision making level to educate the decision makers on sustainability investment, but maybe before going too much on that direction, research should be made on the effects of this sort of activities, into the organization culture on that sort of decision making level [29] and learn from SME size, how they face changes when business models are considered to be changed or big investments are considered.

For this purpose, e.g. ESG (environmental, social, and governance (ESG) criteria) analysis [30] could be used for revealing the potential raw return of investment, connected 
into the close investigation also on organizational culture effects of this investment too, as company's people and its management reactions as result of the investment will have their own effect on final profitability of the investment [31]. Although ESG analysis does not currently have common standards for ratings [32], it has been already shown by researchers' trough over 2000 empirical studies analysis 1970s that circa 90 per cent of those include positive relation between ESG and corporate financial performance [30]. In short, ESG analysis could be considered as one future tool for municipalities for an option to investigate sustainability (financial, managerial and ecological) of environmental investment in near future. Strengthening environmental, social and governance policies in EU, European Commission insurance distribution directive includes ESG [30, 31] factors as a part of risk processes and their decision making as well as also transparency for investors of companies to increase sustainable finance investments.

\section{Conclusions}

Companies should take concrete actions to fight against the climate change and here is one green energy supply possibility introduced. Sustainable investments are not only adding more costs for companies and amortization period needs to be carefully calculated. On another hand, the flue gas scrubber system providers should put a lot of effort on transforming their asset-based business model to include digitalized services [23] that transform the performance gains the unit provides, to factual data which is provided to customers in clear form reports and easily to be read KPI (Key Performance Indicators) measurements. This should be followed by fleet level thinking, collecting this asset-based data from all unit around the world and start to enhance the efficiency of units by managing them like a fleet if units (more efficient spare part handling, global knowledge base for enhancing implementation and "in use" efficiency and so on) [33, 34]. And it would make a lot of sense in nowadays digitalization times to apply the enormous potential of AI platforms to this fleet to improve the design of these flue gas scrubber units in future, based on global level fleet data analysis [35] and by so doing enhancing both the circularity of these units and the on use time efficiency which deduces the environmental impact of the CHP energy factories, where these are implemented into. Also, there would be a good change now to build a selection framework for CHP energy faculties sustainability enhancement options, similarly to the path of studies done on logistics side [36, 37, 38], to help municipalities to focus their environmentally friendly investments on efficient directions.

Additionally, newly developed decision-making tools and analysis would add transparency and effectiveness to the investment process. In this Kuopion Energia case the investment was paid back roughly in 4 years, so the investment was successful both environmentally and financially. Flue gas scrubber investment reduces the emissions significantly and provides solid 3 million euros revenue per each year.

\section{References}

1. G.R. Walther, E. Post, P. Convey, A. Menzel, C. Parmesan, T.J. Beebee, J.M. Fromentin, O. HoeghGuldberg, F. Bairlein, Narute, Ecological responses to recent climate change, 416(6879), 389-395 (2012)

2. M.C. Urban, Science, Accelerating extinction risk from climate change, 348(6234), 571-573 (2015)

3. J. Huang, H. Yu, X. Guan, G. Wang, R. Guo, Nature Climate Change, Accelerated dryland expansion under climate change, 6(2), 166-171 (2016)

4. G.T. Pecl, M.B. Araújo, J.D. Bell, J. Blanchard, T.C. Bonebrake, I.C. Chen, T.D. Clark, R.K. Colwell, F. Danielsen, B. Evengård, L. Falconi, Science, Biodiversity redistribution under climate change: Impacts on ecosystems and human well-being, 355(6332), 1-9 (2017)

5. M.C. Urban, G. Bocedi, A.P. Hendry, J.B., Mihoub, A. Pe'er, A. Singer, J.R. Bridle, L.G. Crozier, L. De Meester, W. Godsoe, A. Gonzalez, Science, Improving the forecast for biodiversity under climate change, 353(6304), 9 (2016)

6. N. Nasiritousi, K. Bäckstrand, Nordic Economic Policy Review, International Climate Politics in the Post-Paris Era, (2019)

7. C.F. Schleussner, J. Rogelj, M. Schaeffer, T. Lissner, R. Licker, E.M. Fischer, R. Knutti, A. Levermann, K. Frieler, W. Hare, Nature Climate Change, Science and policy characteristics of the Paris Agreement temperature goal. 6(9), 827-835 (2016)

8. J. Rogelj, M. Den Elzen, N. Höhne, T. Fransen, H. Fekete, H. Winkler, R. Schaeffer, F. Sha, K. Riahi, M. Meinshausen, Nature, Paris Agreement climate proposals need a boost to keep warming well below 2 C, 534(7609), 631-639 (2016)

9. D. Le Blanc, Sustainable Development, Towards integration at last? The sustainable development goals as a network of targets, 23(3), 176-187 (2015)

10. M. Nilsson, P. Lucas, T. Yoshida, Sustainability, Towards an integrated framework for SDGs: Ultimate and enabling goals for the case of energy, 5(10), 4124-4151 (2013)

11. N. Slawinski, J. Pinkse, T. Busch, S.B. Banerjee, Business \& Society, The role of short-termism and uncertainty avoidance in organizational inaction on climate change: A multi-level framework, 56(2), 253282 (2017)

12. D. Popp International technology transfer, Review of Environmental Economics and Policy, climate change, and the clean development mechanism, 5(1), 131-152 (2011)

13. A.C. Revkin, NEW YORK TIMES BLOG, Four Graphs Bolster Bill Gates's Case for Greatly Boosting Clean-Energy Research, 4.Aug.2015, https://dotearth.blogs.nytimes.com/2015/08/04/fourgraphs-bolster-bill-gatess-case-for-greatly-boostingclean-energy-research/ (2015) 
14. M.R. Halfawy, JCCE, Integration of municipal infrastructure asset management processes: challenges and solutions, 22(3), 216-229 (2008)

15. City of Tampere. Commitment 2050. https://sitoumus2050.fi/selaasitoumuksia\#//details/57FCF202179329E50C25D10 $\underline{9}$ (2019)

16. Finnish Government, https://valtioneuvosto.fi/artikkeli//asset publisher/10616/ennakointi-vahvemminosaksi-tietoon-perustuvaa-paatoksentekoa (2019)

17. Finnish Government, https://valtioneuvosto.fi/en/article//asset publisher/1410837/yksityinen-paaomaglobaalien-ongelmien-ratkaisijaksi (2019)

18. Gaia Consulting Oy, SDGs roadmap to sustainable investments, https://kestavakehitys.fi/ajankohtaista/artikkeli//asset publisher/1410837/hyvinvointiayhteiskunnalle-ja-tuottoa-sijoittajalle (2019)

19. K. Roelich, C.S. Bale, B. Turner, R. Neall, Journal of cleaner production, Institutional pathways to municipal energy companies in the UK: Realising co-benefits to mitigate climate change in cities, 182 , 727-736 (2018)

20. D. Ervin, J. Wu, M. Khanna, C. Jones, T. Wirkkala, Business Strategy and the Environment, Motivations and barriers to corporate environmental management, 22(6), 390-409 (2013)

21. S. Williams, A. Schaefer, Business Strategy and the Environment, Small and medium-sized enterprises and sustainability: Managers' values and engagement with environmental and climate change issues, 22(3), 173-186 (2013)

22. H. Kortelainen, A. Happonen, VTT Blog, From data to decisions - the re-distribution of roles in manufacturing ecosystems, 1 (2018), DOI: 10.13140/RG.2.2.35922.91843

23. H. Kortelainen, A. Happonen, J. Hanski, Lecture Notes in Mechanical Engineering, From asset provider to knowledge company - transformation in the digital era, 333-341 (2019)

24. H. Tomić, S. Mastelić Ivić, M. Roić, ISPRS International journal of geo-information, Land consolidation suitability ranking of cadastral municipalities: Information-based decision-making using multi-criteria analyses of official registers' data, 7(3), p. 87 (2018)

25. T. Eskelinen, T. Räsänen, U. Santti, A. Happonen, M. Kajanus, TIM, Designing a business model for environmental monitoring services using fast MCDS innovation support tools, 7(11), 36-46 (2017)

26. J. Porras, A. Knutas, J. Ikonen, A. Happonen, J. Khakurel, A. Herala, 52nd HICSS, Code camps and hackathons in education - literature review and lessons learned, 7750-7759 (2019), DOI:

10.24251/hicss.2019.933

27. J. Porras, J. Khakurel, J. Ikonen, A. Happonen, A. Knutas, A. Herala, O. Drögehorn, 2018 ICSE, Hackathons in software engineering education lessons learned from a decade of events, 40-47 (2018), DOI: 10.1145/3194779.3194783

28. U. Santti, A. Happonen, H. Auvinen, 13th Eureca, Digitalization Boosted Recycling: Gamification as an Inspiration for Young Adults to do Enhanced Waste Sorting, 14 (2019)

29. U. Santti, T. Eskelinen, M. Rajahonka, R. Villman, A. Happonen, TIM, Effects of Business Model Development Projects on Organizational Culture: A Multiple Case Study of SMEs, 7(8), 15-26 (2017), DOI: $10.22215 /$ timreview/1096

30. G. Friede, T. Busch, A. Bassen, tafjsustf, ESG and financial performance: aggregated evidence from more than 2000 empirical studies, 5(4), 210-233 (2015)

31. S. Kotsantonis, C. Pinney, G. Serafeim, Journal of Applied Corporate Finance, ESG integration in investment management: Myths and realities, 28(2), 10-16 (2016)

32. S. Utz, M. Wimmer, Journal of Asset Management, Are they any good at all? A financial and ethical analysis of socially responsible mutual funds, 15(1), 72-82 (2014)

33. H. Kortelainen, A. Happonen, S-K. Kinnunen, Lecture Notes in Mechanical Engineering, Fleet Service Generation - Challenges in Corporate Asset Management, 373-380 (2016)

34. S-K. Kinnunen, A. Happonen, S. Marttonen-Arola, T. Kärri, IJSEAM, Traditional and extended fleets in literature and practice: Definition and untapped potential, ISSN: 1759-9733, 20 (2019)

35. M. Ghoreishi, A. Happonen, ICEPP 2019, New Promises AI Brings into Circular Economy Accelerated Product Design: Review on Supporting Literature, 11 (2019)

36. D. Minashkina and A. Happonen, IJSCIM, Systematic literature review and research gap issues on 3rd party logistics operator selecting WMS for efficient operations for customers, p. 19 (2019)

37. D. Minashkina, A. Happonen, ICEPP 2019, Decarbonizing warehousing activities through digitalization and automatization with WMS integration for sustainability supporting operations, 8 (2019)

38. D. Minashkina, A. Happonen, $13^{\text {th }}$ Eureca, $A$ Development of the Warehouse Management System Selection Framework as Academic-Industrial Collaboration Work with Sustainability Considerations, 14 (2019) 